\title{
GESTAÇÃO NA ADOLESCÊNCIA: A CONSTRUÇÃO DO PROCESSO SAÚDE-RESILIÊNCIA.
}

\author{
Adolescence Pregnancy: The Construction of the Health-Resilience Process.
}

Embarazo en la Adolescencia: La Construcción del Proceso de Salud de la Resiliencia.

Patricia Mônica Ribeiro'

Dulce Maria Rosa Gualda

\section{RESUMO}

Trata-se de um estudo etnográfico que tem como objetivo compreender a vivência das adolescentes durante a gestação e no processo de nascimento do seu filho. 0 método utilizado para a coleta de dados foram entrevistas semiestruturadas e observação participante. Na coleta de dados foram realizadas notas de campo. As entrevistas foram transcritas, transcriadas na forma de narrativas, identificando os tons vitais. A construção das narrativas derivou na organização das categorias empíricas a partir da leitura cuidadosa dos dados, o que resultou na elaboração de três temas. 0 processo saúde-resiliência ficou caracterizado a partir do entrelaçamento dos temas revelados, ou seja, o suporte social oferecido à adolescente consegue favorecer as mudanças necessárias para o pleno desenvolvimento pessoal da gestante, a qual se torna mãe adolescente responsável, cuidadosa, livre para tomar decisões e consciente de seu papel na sociedade.

Palavras-chave: Adolescência. Gestação. Enfermagem.

\begin{abstract}
This is an ethnographic study that aims to understand the experience of adolescents during pregnancy and birth process of their child. The method used for data collection was semistructured interviews and participant observation. In data collection there were field notes. The interviews were transcribed, transcreated in a narrative way, identifying the critical vital tones. The construction of narratives derived from the organization of the categories from the perusal of the data, which resulted in the development of three themes. The process of health-resilience was characterized from the interweaving of the themes developed, and the social support offered to adolescents encourage the changes necessary to the full personal development of the pregnant woman, who becomes a teenage mother responsible, careful, free to take decisions and aware of their role in society.
\end{abstract}

Keywords:. Adolescence. Pregnancy. Nursing.

\section{Resumen}

Se trata de un estudio etnográfico que tiene como objetivo comprender la experiencia de los adolescentes durante el embarazo y alumbramiento de su hijo. El método utilizado para la recolección de datos fue la entrevista seme-estructurada y observación participante. En la coleta de datos fueron realizadas notas de campo. Las entrevistas fueron transcritas, recreadas en forma de narraciones, identificando los tonos críticos. La construcción de narrativas ha derivado de la organización de las categorías de la lectura de los datos, lo que resultó en el desarrollo de tres temas. La capacidad de recuperación de la salud se caracterizó desde el cruce de los temas desarrollados, es decir, el apoyo social que ofrece a los adolescentes pueden fomentar los cambios necesarios para el pleno desarrollo personal de la mujer embarazada, que se convierte en una madre adolescente responsable y cuidadosa, libre para tomar decisiones y consciente de su papel en sociedad.

Palabras claves: Adolescencia. Embarazo. Enfermería

${ }^{1}$ Enfermeira. Doutora pela Escola de Enfermagem da Universidade de São Paulo (USP). Professora da Faculdade de Enfermagem e Faculdade de Medicina da Universidade José do Rosário Vellano UNIFENAS, Alfenas-MG. Brasil. E-mail: tinero@oi.com.br Professora ${ }^{2} T$ Titular do Departamento de Enfermagem Materno-Infantil da Escola de Enfermagem da USP. São Paulo-SP. Brasil. E-mail: drgualda@usp.br 


\section{INTRODUÇÃO}

Adolescência é tida como um conceito ${ }^{1}$ que possui dois significados: por um lado, refere-se à puberdade corporal tardia e à pós-puberdade, mas, por outro lado, significa a superação psicológica do amadurecimento corporal e sexual, isto é, a adolescência representa a acomodação da personalidade infantil à puberdade, é uma expressão da interação psicossocial e, por conseguinte um fenômeno sociocultural.

Cada cultura e cada época resolvem, à sua maneira, a passagem da infância para a idade adulta, pois em várias sociedades tribais, após um ritual de iniciação, que pode durar dias ou semanas, os jovens são admitidos no mundo adulto como seres completos, autônomos e responsáveis. $\mathrm{Na}$ sociedade ocidental, a adolescência tem se transformado em longa moratória, cheia de angústias e incertezas, sem rituais claros de passagem. Os jovens dos anos viveram muitas utopias: as revoluções armadas, 0 socialismo, a paz e 0 amor. Nos anos noventa, a sociedade globalizada uniformizou produtos, costumes, moda, ideais de vida e sonhos. Sem raízes, sem referências para construir a sua identidade, não tinham contra o quê se rebelar ou a quem hostilizar; estavam indiferentes ao mundo adulto. ${ }^{2}$

Hoje, parece haver uma mudança quanto à conscientização ecológica dos jovens, à importância das questões mundiais, mas continuamos a vivenciar a influência da globalização, da mídia, da falta de limites e da mudança de valores na família e na sociedade. E é nesse contexto que a gestação na adolescência vem aumentando sua incidência, ou seja, nesse contexto de vulnerabilidade em que os adolescentes vivem. ${ }^{2}$

Buscando na literatura estudos com enfoque sobre a gestação na adolescência, a maior parte tem como marco teórico o conceitual cronobiomédico. Alguns estudos associam a gravidez na adolescência à assistência prénatal deficiente; maior incidência de patologias durante e após a gestação; maior risco de morbimortalidade para o concepto e maior risco psicossocial. ${ }^{3-5}$ Outros autores ainda referem que a gestação na adolescência representa um problema complexo no âmbito da saúde pública, que requer uma abordagem teórica segura e humanizada, em que a linguagem utilizada por profissionais prejudica 0 entendimento das orientações. ${ }^{6,8}$

Estudos mais recentes vêm sendo realizados e apontam para uma mudança na interpretação da gestação na adolescência, pois na saúde pública persiste o discurso normativo que considera o evento um fator de risco social. ${ }^{9,10}$ Nessa visão, a gravidez resulta da pobreza, da precariedade e da falta de acesso aos serviços de saúde, portanto, é considerada como um reforço à pobreza e à marginalidade. Porém, essa visão causal é uma visão reducionista, porque mesmo que a gravidez na adolescência frequentemente se encontre associada a um contexto de desvantagem social, é preciso considerar que sua ocorrência já se dá em um âmbito pontuado por opor tunidades restritas e poucas opções de vida e marcado por interrupções na trajetória escolar. ${ }^{11} \mathrm{~A}$ experiência da gravidez e da maternidade rompe com a trajetória definida como ideal pelas famílias, ou seja, obter uma formação escolar,conseguir um trabalho, ter autonomia financeira e, depois, a constituição de sua família, e, por isso, emerge como um problema social e risco a evitar-se. A organização da atenção integral à saúde do adolescente tem sido um desafio para a saúde e para a sociedade, pois, nos dias atuais, a necessidade de implantação de políticas públicas para a adolescência tornou-se obrigatória, considerandose 50 milhões de adolescentes e de jovens no Brasil. ${ }^{3}$

A gestação na adolescência pode representar um problema pessoal ou do âmbito da Saúde Pública, em que as transformações da sociedade trazem à tona as peculiaridades da adolescência, desde a antiguidade até os dias atuais. Minha experiência com gestantes adolescentes levou-me a buscar outros conceitos que poderiam ajudar a clarificar o tema, pois, como desejava aprofundar a questão da gestação na adolescência, precisei levar em conta as adolescentes que já viveram uma gestação, estão na segunda ou terceira, não possuem apoio da família e do companheiro, ou apenas de um deles; porém, com as dificuldades e adversidades, conseguem seguir adiante com a gestação, desejavam engravidar, optam pelo relacionamento ou desistem, mas, acima de tudo, cuidam da criança e têm projetos de vida. De que forma as adolescentes gestantes que vivenciam situações adversas conseguem sair fortalecidas, mesmo estando expostas a fatores de risco antes, durante e depois da gestação? Parte disso o meu interesse em aprofundar o conhecimento sobre este tema, ou seja, a experiência da adolescente na gestação e no tornar-se mãe, e que recursos são utilizados na vivência desse processo.

\section{OBJ ETIVO}

Assim, propus como objetivo deste estudo compreender a vivência das adolescentes durante a gestação e no processo de nascimento do seu filho.

\section{REFERENCIAL TEÓRICO}

Este estudo foi ancorado na Antropologia Médica. Para entender o contexto na sua totalidade, recorri a este referencial como suporte para o estudo, pois a Antropologia Médica, tal qual a Antropologia, tem como referência a cultura. A cultura representa o conhecimento compartilhado e aprendido de uma sociedade e serve de base para sua ação. A cultura de um grupo está sempre em movimento na 
medida em que ocorrem as mudanças na condição de vida desse grupo. Para se compreender e analisar saúde e doença, em qualquer sociedade, é preciso abranger os comportamentos individuais, as interações e a estrutura social no contexto cultural. ${ }^{12}$

Os estudos da Antropologia Médica têm como foco a subjetividade, a linguagem e os processos sociais da saúde e da doença. 0 ponto fundamental desta área são as questões biológicas e culturais, relacionadas ao sofrimento humano e aos esforços ritualizados no manejo de desordens e riscos pessoais, com a investigação da experiência humana e das bases existenciais da cultura.

A doença é fundamentalmente biocultural, sempre biológica e sempre cultural, situada na interseção da biologia com a cultura. Representa a perda "do destino e do mapa" que serve de guia na trajetória de vida, e, ao presenciar a experiência de reconstrução do mapa da vida da pessoa doente, aqueles que fazem parte do seu mundo também reelaboram o seu próprio mapa. ${ }^{13: 18}$ Essa afirmação vem ao encontro da questão da gestação na adolescência, porque a gravidez acontece como uma perda do guia ou trajetória de vida para a adolescente, e a literatura médica mostra que os autores têm grande preocupação com as consequencias de uma maternidade precoce para o binômio mãe e filho, em uma visão vertical, unificada e objetivada que reduz 0 caráter humano da maternidade ao caráter puramente biofisiológico.

Assim, a questão da gestação na adolescência deve ser compreendida além do processo biofisiológico, pois apresenta características peculiares que têm significado diferenciado para cada mulher; é vivenciada de maneira diferente em cada cultura, constituindo-se, portanto, em um processo de saúde que traz mudanças significativas em cada etapa do ciclo de vida. Quando tratamos a gestação como processo, temos uma perspectiva mais compreensiva, reunindo e englobando as mulheres e suas famílias, na medida em que tomam contato, respondem e se adaptam às situações.

Portanto, no intuito de buscar uma forma humanizada do cuidar no processo da gestação na adolescência, utilizei a Antropologia Médica, que fundamenta a abordagem compreensiva e 0 acesso às vivências, aos significados e às experiências vividas pelas adolescentes.

Diante das minhas inquietações, e ainda buscando respaldo na literatura, coloco o conceito de resiliência, que é um chamado a centrar-se em cada indivíduo como alguém único, é enfatizar as potencialidades e os recursos pessoais que permitem enfrentar situações adversas e sair fortalecido, apesar de estar exposto a fatores de risco. ${ }^{14}$ Neste estudo, utilizei o enfoque anglo-saxônico ou psicobiológico da resiliência que dá importância à interação pessoa-ambiente e às diferentes formas nas quais os indivíduos respondem ante as ameaças e aos desafios do meio. Situa a pessoa como referência de um sistema de interações favoráveis ou desfavoráveis à sua organização e desenvolvimento.

0 respaldo teórico da Antropologia Médica com enfoque no significado das mudanças ocorridas na vida das adolescentes grávidas, ligado ao conceito da resiliência, permitiu compreender a vivência e os mecanismos que as colaboradoras verbalizaram no enfrentamento da gestação. Essa escolha deu-se a partir da minha experiência e da revisão de dados epidemiológicos e conceitos teóricos da literatura sobre o processo saúde-doença. 0 exame dos dados mostra que a gravidez pode ter resultados negativos para as adolescentes e trazer problemas de desenvolvimento para seus filhos, mas nem sempre é isso que acontece. Algumas adolescentes podem manifestar problemas psicossociais e no desempenho do papel materno, enquanto outras não. Esse referencial pareceu ser útil para examinar e interpretar as diferenças individuais, as experiências e seus resultados para as adolescentes expostas ao desafio da gestação precoce. Portanto, três aspectos do conceito de resiliência são levados em conta neste estudo: a resiliência enquanto processo, a exposição às adversidades e a adaptação diante da adversidade. ${ }^{14}$

\section{METODOLOGIA}

Este estudo foi desenvolvido como pesquisa qualitativa ${ }^{7}$ ancorada na Antropologia Médica. Respaldeime na etnografia, porque pretendia uma descrição detalhada da experiência de pessoas, no caso as adolescentes, pertencentes a um determinado contexto cultural, pois tem como pressuposto que um grupo de indivíduos cria uma cultura que orienta a visão de seus membros e a forma pela qual eles estruturam suas experiências. ${ }^{15} \mathrm{~A}$ Etnografia é, por definição, colaborativa, isto é, Etnografia Colaborativa, ${ }^{16}$ em que colaborar significa literalmente trabalhar junto, especialmente em um esforço intelectual. Enquanto a colaboração é o centro da prática da Etnografia, realizar mais deliberadamente e explicitamente Etnografia Colaborativa implica recolocar a prática colaborativa em todos os estágios do processo etnográfico. Assim, nas comunidades onde trabalhamos, estudamos ou praticamos, possivelmente não podemos cumprir nosso ofício sem nos envolvermos no contexto da sua realidade, na sua vida diária.

Para a realização deste estudo, foram adotados os seguintes critérios: ser adolescente entre 10 e 19 anos; iniciar acompanhamento pré-natal; estar em idade gestacional de 4 a 20 semanas, porque 0 estudo foi 
desenvolvido ao longo de todo o processo de gestação, parto e puerpério de cada colaboradora. 0 contexto cultural deste estudo foi um município do Sul de Minas Gerais.

A coleta de dados foi realizada por meio de entrevistas semiestruturadas e observação participante. Iniciou-se em maio de 2007 e teve o término em novembro de 2008, em um total de 18 meses. Foram realizadas várias entrevistas com todas as colaboradoras, porque pretendia acompanhar todo o processo gestacional, parto, puerpério e a nova vida da mãe adolescente. Nesse mesmo período, foi realizada a observação participante que envolve não somente ganhos no acesso e na imersão em novos mundos sociais; mas, também, produz escritos e descrições que trazem visões desses mundos para outros e permite que 0 pesquisador apreenda a perspectiva do grupo por meio de imersão na cultura.

As entrevistas aconteceram em vários momentos durante o desenvolvimento desta pesquisa. No início deste processo, as entrevistas foram conduzidas com as seguintes questões nor teadoras: Como é para você ser adolescente e estar grávida? Como você se vê nessa condição? Conte-me como você está vivenciando esta gravidez desde o momento que soube que esperava um filho. Após o nascimento, utilizei as seguintes questões norteadoras: Mudou alguma coisa em sua vida? 0 quê? 0 que tem feito ante essas mudanças? As entrevistas foram transcritas, textualizadas e transcriadas ${ }^{17}$ por mim para a construção das narrativas e identificação dos tons vitais.

A ética da pesquisa foi preservada pela garantia de anonimato às colaboradoras, pela obtenção do Termo de Consentimento Livre e Esclarecido para o emprego de suas informações com finalidade exclusivamente científica, conforme determina a Resolução nº196 de 1996 do Conselho Nacional de Saúde (CNS), que trata das Diretrizes e Normas Regulamentadoras de Pesquisas em Seres Humanos. Este estudo foi aprovado pelo Comitê de Ética em Pesquisa da Escola de Enfermagem da Universidade de São Paulo sob número 646/2007, em 25 de maio de 2007. Como as colaboradoras foram gestantes adolescentes, a assinatura do referido Termo de Consentimento foi realizada pelas suas respectivas mães ou responsáveis, na presença da pesquisadora.

Nome de escolha do grupo para a Boneca de Parto

0 Grupo Cultural denominado "As Sete Marias" foi formado por sete gestantes adolescentes, residentes na zona urbana e rural do município. Esse nome foi escolha do grupo, referindo ao nome da Boneca de Parto "Maria". Para evitar a dificuldade no reconhecimento de cada colaboradora, decidi usar vários nomes derivados de "Maria" e criei: Maria, Maria Ana, Maria Rita, Maria Isabel,
Maria Alice, Maria Sílvia e Mariana, cada uma com a sua singularidade, sua história de vida, seu mecanismo de enfrentamento da gestação, do parto, do puerpério, e, sobretudo, sua vida como mãe adolescente.

\section{RESULTADOS E DISCUSSÃO}

0 Processo de tratamento dos dados iniciouse com a transcrição das entrevistas, sendo que, somente após a transcrição e análise da primeira entrevista, foi agendada a segunda e, assim, sucessivamente. 0 processo de transcrição e transcriação levou à construção das narrativas e identificação dos tons vitais. As narrativas transcriadas a partir das entrevistas foram categorizadas, em um processo que requeriu sistematização dos dados. A leitura e as releituras das narrativas evidenciaram o movimento das falas que entrelaçavam os tons vitais, conceitos e atitudes das colaboradoras. Nessas falas, as adolescentes deixavam vir à tona o processo gestacional e as mudanças que aconteceram em suas vidas e como esse processo se realiza em cada família e no coletivo. As narrativas tiveram como tons vitais os depoimentos que se seguem:

...Hoje sou uma adolescente feliz, como filha, como mãe, como esposa, sou feliz! [ Maria]

...Minha vida agora está bem melhor, estou feliz![ Maria Ana]

...Estou tranquila, minha vida está sossegada...minha mãe me ajuda bastante.... minha vida mudou muito, mas eu gostei demais....gostei demais.. [ Maria Rita]

...Minha vida mudou, mas eu estou gostando... antes eu olhava criança de outra casa, e agora, eu cuido do meu filho. Estou feliz assim![ Maria Isabel]

....Estou feliz, era isso mesmo que eu queria. Eu queria isso tudo.Valeu à pena![ Maria Alice]

....Um dia era isso que eu queria...veio antes, mas está do mesmo jeito que eu queria... [ Maria Silvia]

...Mesmo sendo adolescente, sou mãe e gosto de ser assim... [Mariana] 
A construção das narrativas resultou na organização das categorias empíricas a partir da leitura cuidadosa dos dados. As categorias encontradas totalizam sete principais e suas respectivas subcategorias.

Categoria 1- Identidade e Situação familiar: refere-se à identificação das adolescentes no contexto familiar, bem como revela sua posição na família, seu relacionamento com os irmãos, pais e com sua infância. Neste estudo, o grupo de colaboradoras revelou fazer parte de famílias estruturadas com a presença de pai, mãe e irmãos. Como é revelado nesta fala:

Eu sou Maria Isabel, tenho dezessete anos, sou a filha mais velha da minha casa e tenho duas irmãs (...) minha infância foi tudo normal.[Maria Isabel]

Categoria 2-Planejamento da gravidez: a ocorrência da gestação é resultante do desejo de ter ou não filhos. Nesse sentido, as subcategorias que explicam o planejamento da gravidez podem ser constatadas como:

a) Desejavam a gravidez: várias adolescentes revelaram que tanto elas quanto os companheiros desejavam ter filhos; como podemos observar nos depoimentos a seguir:

...Eu queria esse neném, então ele está trazendo muita felicidade para mim e para meu marido...[MariaAna]

...Porque não só eu queria ter filho, como meu namorado também queria ter... [Maria Rita]

b) Não desejavam, mas engravidaram: para algumas adolescentes, mesmo não desejando a gravidez, essa ocorreu pela dificuldade do uso de anticoncepcional devido aos efeitos colaterais manifestados e do desconhecimento do mecanismo de ação do medicamento, como o depoimento que se segue:

..Eu tomei pílula um tempo, parei porque passava mal e achei que não ia engravidar, porque achei que meu organismo tinha absorvido bastante, então, não ia engravidar... [Maria]

Categoria 3-Descobrir-se grávida: a fala das adolescentes revela os significados distintos apreendidos, baseados em suas experiências. Essa categoria abrange as subcategorias que seguem: a) Constatação da gestação: refere que a maneira de perceber a gestação nesse cotidiano social e cultural é peculiar a cada uma delas, como pode ser observado nessas falas:

...Eu, pra mim, eu não estava grávida... quem achou que eu estava mesmo foi ele... também pra mim nunca atrasou... regulava, sempre adiantava, vinha com 21 dias, 20, nunca atrasava...[Maria]

...Quando eu fiquei sabendo que estava grávida, eu estava lá na casa da mãe dele, deu tontura em mim só nesse dia, depois não me deu mais... [Maria Rita]

b) Comunicação da gravidez aos familiares: a partir da constatação da gravidez, as adolescentes revelam suas expectativas em relação à reação dos pais e da rede social diante do ocorrido. Algumas colaboradoras revelaram medo da reação ou desapontamento dos pais, enquanto outras não, como se percebe nessas falas:

...Eu fui a primeira filha que fez isso... só que ele tinha esperança em mim, entendeu?...[Maria]

....Eu fiquei com medo quando eu soube, de ela (mãe) me xingar, mas graças a Deus tudo correu bem, ela não xingou... [Maria Rita]

As adolescentes revelaram o que aconteceu diante do impacto da notícia, considerando suas expectativas prévias em relação à reação dos pais diante do impacto da notícia. Algumas famílias receberam bem a notícia da gravidez:

...Minha mãe ficou feliz com a notícia da minha gravidez... [Maria Ana]

...Minha mãe ficou feliz, me apoia bastante... [Maria Isabel]

Outras famílias não aceitaram, e as adolescentes revelaram o conflito criado entre pais e filhas, como é revelado nessa fala:

...Foi ele (companheiro) que contou, pediu perdão para o meu pai... meu pai no dia ficou maior louco xingou, xingou mais ele do que eu...[Maria]

A reação dos pais diante do impacto da notícia revela que em algumas famílias a gestação é recebida com naturalidade, enquanto, em outras, existe uma dificuldade de aceitação. Esse fato demonstra que a gestação quando já ocorreu anteriormente, ou quando 
há permissão para o relacionamento da adolescente, é recebida com felicidade, como se observa no depoimento a seguir:

...Meus pais aceitam bem a gravidez, porque eu já sou a terceira na família... [Maria Silvia]

Categoria 4-Suporte social durante o processo: essa categoria engloba três subcategorias: a) Reconciliação após quebra de relacionamento com a família: 0 comportamento dos pais diante do impacto da notícia da gravidez sofreu mudanças durante o desenvolvimento da gestação e ou após o nascimento da criança, fato esse que é evidenciado nessa fala:

...Hoje meu pai quer fazer de tudo para mim e para a criança... Tudo, tudo, tudo, que você possa imaginar...Tudo mudou... [Maria]

Ainda, as adolescentes que tiveram mais de uma gestação relataram que as experiências anteriores favoreceram a aceitação dos pais e dos familiares, mantendo um bom relacionamento entre eles, o que é revelado nessa fala:

...Depois que o bebê nasceu é que voltamos a conversar, quer dizer, conversar com minha mãe e meu pai (...) a segunda gestação foi normal, assim, porque eu já estou com o Felipe, não sofri tanto...[Mariana]

b)Apoio dos pais e familiares: durante 0 período gestacional a mudança no comportamento dos pais foi traduzida pelo apoio recebido, principalmente, da mãe ou da sogra. As adolescentes valorizaram o apoio recebido e a aceitação da gestação pela família. Esse fato é evidenciado nessas falas:

...Minha mãe está do meu lado, minha família está do meu lado... [Maria]

...Minha família está me ajudando bastante, todos, meu pai, minha mãe, meu companheiro...[Maria Alice]
...Minha sogra está me ajudando bastante, minhas cunhadas também, minha mãe foi me ver só no hospital... [Mariana]

c) Apoio e participação do companheiro: enquanto algumas adolescentes viviam maritalmente com os companheiros, outras permaneceram na casa dos pais. As adolescentes optaram viver com o companheiro; algumas se casaram durante a gestação, outras se casarão após o parto, e outras decidiram viver maritalmente com o companheiro e com o consentimento dos pais. 0 apoio recebido do companheiro e seu envolvimento durante o período gestacional, parto e puerpério também mostraram-se significativos no comportamento das adolescentes. Esse fato é evidenciado nessas falas:

...Na gravidez ele só não frequentou o médico comigo porque ele tem dois empregos (...) eu fico aqui (casa dos pais) durante a semana e vou para minha casa no final de semana... [Maria]

...Com meu outro companheiro eu terminei com ele porque ele não me dava atenção (...) Esse meu namorado atual, pai deste bebê, gosta dos meus outros filhos, as crianças chamam de pai (...) esse agora dá atenção para os meus filhos (...) nós vamos casar no ano que vem... [Maria Alice]

d) Apoio material e financeiro: Nesse grupo percebeu-se que não houve impedimento para 0 desenvolvimento gestacional devido à situação financeira, pois todas moram em casa própria, algumas trabalhavam e todas estavam estudando no início da gravidez. Enquanto algumas decidiram ter sua própria casa, outras permaneceram na casa dos pais, passando a viver com a família nuclear nesse mesmo ambiente, que é revelado nessas falas:

... O meu namorado falou para ela (irmã) que ia sair da casa e alugar outra para ele comigo... agora ele está trabalhando e já alugou uma casa... quem casa quer casa, não é?..[Maria]

...Eu sempre morei aqui, moro com meus pais. Mais para frente vou construir aqui, 
mas por enquanto vou morar aqui, com meu pai e minha mãe... [Maria Silvia]

Categoria 5-Mudança de comportamento: a descoberta e o desenvolvimento da gestação trazem mudanças significativas no comportamento das adolescentes, como foi verbalizado nessas falas:

...Agora, as coisas vão ser bem diferentes, eu 14 anos mãe (...) sei lá! A responsabilidade vai ser mais (...) minha cabeça está diferente agora (...) hoje eu faço as coisas pensando no que está dentro de mim, não pode sofrer as consequências mais para a frente...[Maria]

...Antes eu saía muito, ia à festa, agora eu parei porque não tem como, minhas colegas me chamavam para sair, mas, agora não vou, mas, tudo bem... [Maria Isabel]

Categoria 6- Vivência do papel materno: revela os sentimentos em relação à experiência do nascimento do filho, em que a presença da mãe durante o parto tranquilizou e facilitou a aceitação da dor do parto, como é revelado nessa fala:

...Meu filho nasceu de parto normal, foi tranquilo. Minha mãe ficou comigo o tempo todo, ela disse que era assim mesmo...[Maria Isabel]

Nos relatos as adolescentes apontaram as práticas de cuidado ao filho. Para essas adolescentes, o cuidado com os bebês e a amamentação foram verbalizados de forma positiva e prazerosa. As participantes do estudo revelaram também a necessidade de ajuda no início dos cuidados, considerando a mãe a principal fonte de apoio.

...Ele nasceu dia 22 de outubro... Eu tenho bastante leite, estou amamentando, só não dou banho porque tenho medo de derrubar, mas faço tudo, troco, ele dorme perto de mim...[Maria]

...Amamentei meu filho no peito, e até hoje continuo amamentando, porque ele fez dois meses dia dezoito, está gordinho. Quando ele nasceu eu vim para a casa da minha mãe, porque ela me ajuda muito, me diz como fazer as coisas para o neném, e eu vou continuar aqui até eu me casar. Aqui no sítio é bem melhor para mim e para o neném... [Maria Isabel]

Categoria 7- Perspectivas para o futuro: À medida que as adolescentes desempenham o papel materno, estabelecem suas perspectivas quanto à criação dos filhos e ao seu futuro. Essa categoria abrange as seguintes subcategorias:

a) Planos em relação à criação dos filhos: As adolescentes valorizam a experiência e têm planos de uma vida melhor para si e para seus filhos, como é evidenciado nessa fala:

...Daqui para frente eu espero que eu possa cuidar do meu filho melhor. Espero que eu possa dar uma coisa melhor para ele do que eu não tenho para mim e para meu marido... [Maria Ana]

b) Planos pessoais: Todas as colaboradoras revelaram seu projeto de vida. Algumas consideram a continuidade imediata do estudo, enquanto outras decidiram adiar até o crescimento do bebê. Todas se revelaram motivadas para o futuro como mães, com suas famílias formadas antes da gestação e mantidas durante e após o parto, o que é verbalizado nessas falas:

...Antes de engravidar eu não tinha esse plano, mas depois que engravidei, planejei tudo: minha casa, minha vida com meu namorado, tudo (...) Por enquanto não vai dar para voltar a estudar, mas depois de dois anos eu volto para a escola... [Maria]

...Ano que vem eu volto a estudar e continuo cuidando dela, porque eu cuido dela, dou banho, faço tudo, e estou feliz... [Maria Ana]

À medida que as adolescentes desempenharam o papel materno, estabeleceram suas perspectivas quanto à criação dos filhos e ao seu futuro. As adolescentes valorizaram a experiência e tinham planos de uma vida melhor para si e para seus filhos.

Para facilitar a compreensão das categorias reveladas e suas subcategorias, os dados apresentados acima são esquematizados na representação gráfica que se segue: 
Figura 1. Trajetória da gravidez na adolescência
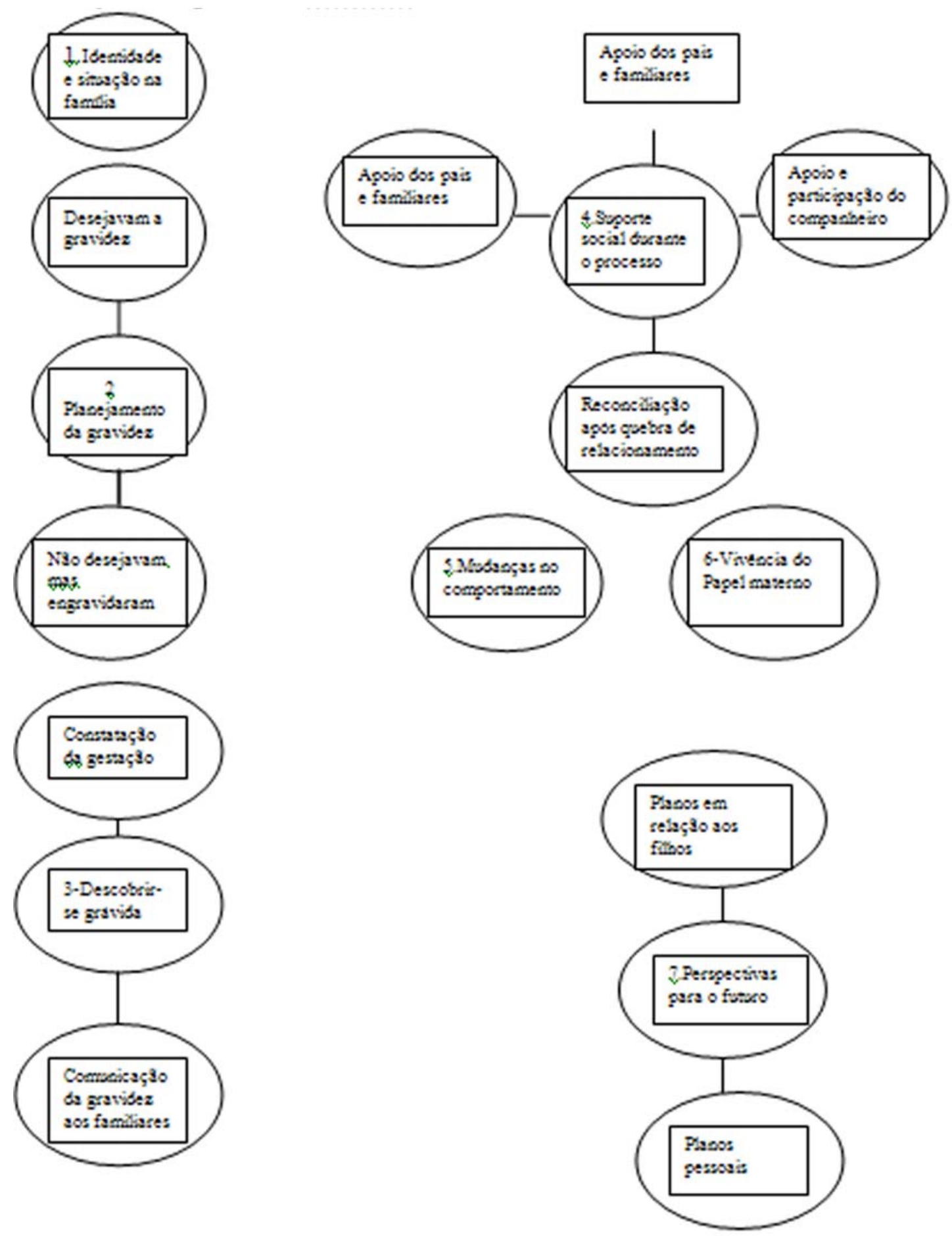

A compreensão do enfrentamento do processo gestacional na adolescência e a construção da resiliência exigiram um aprofundamento teórico constante e árduo.
Respaldo-me no modelo denominado Expanded Model of Adolescent Parenting and Resilience ${ }^{18}$ para compreender e descrever a gestação na adolescência. 
Figura 2. Modelo adaptado de Borkowski, Whitman,Farris.An Expanded Model of Adolescent Parenting and Resilience, 2008.

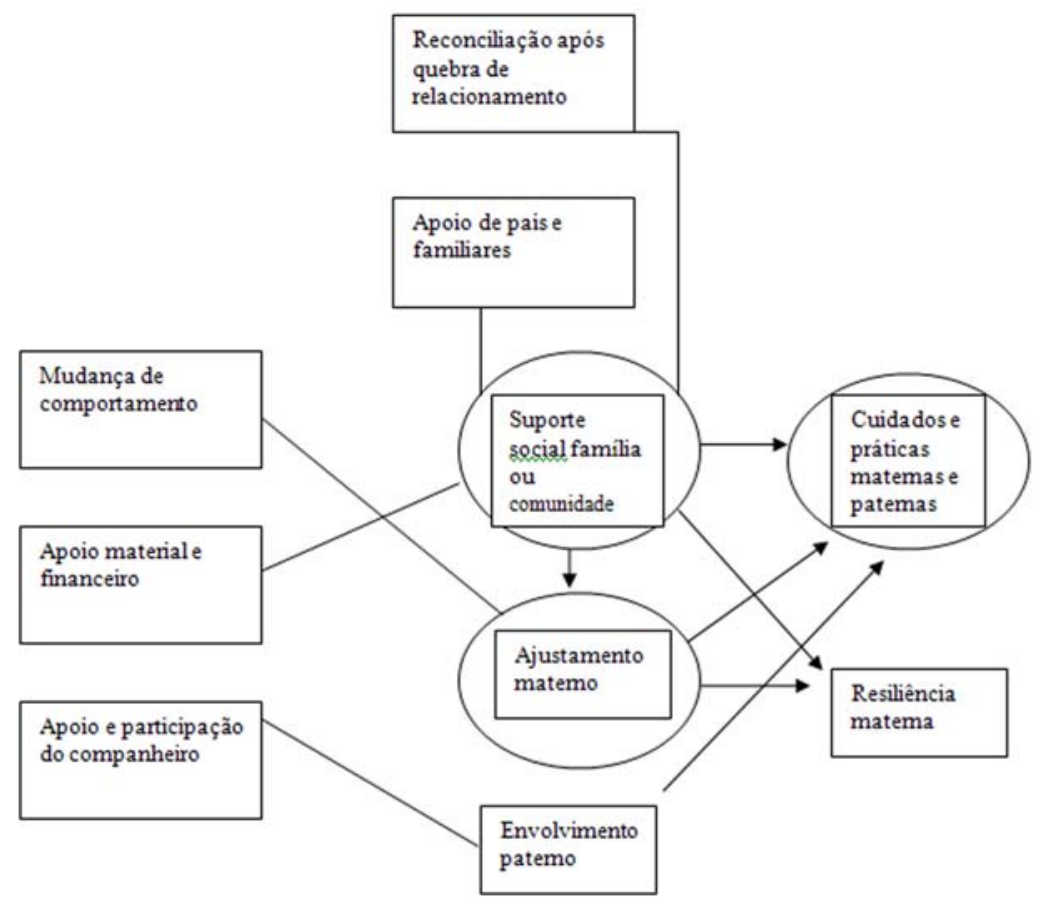

Neste estudo observa-se que a trajetória da gestação na adolescência levou à construção da resiliência. As adolescentes vivenciaram situações adversas, como expulsão da casa paterna, brigas, desentendimentos familiares, mas foram capazes de desenvolver atributos pessoais: ${ }^{14}$ eu tenho pessoas do entorno em quem confio e que me querem incondicionalmente - essas pessoas se revelaram nas mães, sogra e companheiro como apoio incondicional; eu sou uma pessoa pela qual os outros sentem apreço e carinho - todas revelaram um bom convivio familiar com pais e irmãos; eu estou disposto a me responsabilizar por meus atos - todas evidenciaram responsabilidade pela gestação e pela criação da nova família como um evento positivo que faz parte da vida de cada uma delas; eu posso falar sobre coisas que me assustam ou inquietam - todas as colaboradoras vivenciaram esse atributo desde a aceitação em participar desta pesquisa, pois foi uma maneira de partilhar seus medos, angústias, dúvidas, em relação à família e mesmo em relação à pesquisadora. Todas desenvolveram esses atributos pessoais no decorrer da experiência da gestação e após o parto, pois as situações de adversidade não são estáticas mudam e requerem mudanças nas condutas resilientes, fato esse que ficou evidenciado durante todo o desenvolvimento da gestação, pois o processo gestacional não é estático, muda e exige mudanças no comportamento resiliente. Isso pode explicar a superação de conflitos, medos e insegurança que a própria gestação impõe sobre a adolescente, mas, ao mesmo tempo, demonstra a preparação e o aprendizado das adolescentes na construção do seu projeto de vida. Entende-se aqui que esta "superação" é também um processo, pois permite que se saia fortalecida, transformada e vencedora de situações adversas. A leitura e releitura cuidadosa dos dados das categorias empíricas resultou na elaboração dos três temas:

Suporte Social: A partir do apoio recebido, as adolescentes conseguem desenvolver habilidades resilientes e vivenciam a gestação com capacidade para criar expectativas em relação aos filhos e ao futuro. Ressalta-se neste estudo a aceitação por parte dos pais das adolescentes durante a gravidez e após o nascimento dos bebês, 0 acolhimento da nova família nuclear, sendo que esse fato vem mostrar a mudança de comportamento dos pais diante da gestação na adolescência. Portanto, o suporte social é extremamente importante para a adolescente, pois nenhuma das colaboradoras ficou desamparada durante todo o desenvolvimento da gestação, parto, puerpério e na nova vida com sua família nuclear.

Mudança: A mudança na trajetória de vida ocorrida pela gestação na adolescência é revelada como um acontecimento bom que traz satisfação e felicidade, apesar das adversidades. As adolescentes se revelam mães satisfeitas, felizes, com planos para o futuro, para manutenção das famílias nucelares e se posicionam com domínio da situação vivida. São livres para decidir se desejam retornar aos estudos ou não, ou continuar. Essa mudança que a gestação traz à adolescente mostra a autonomia que ela adquire quando se desenvolve 
como uma pessoa resiliente. Como mãe adolescente resiliente, se declara independente, responsável, segura e confiante no futuro.

Mesmo sendo adolescente, sou mãe e gosto de ser assim: 0 papel materno revelado mostra a adaptação das adolescentes aos cuidados com os bebês, e o ser mãeadolescente é valorizado pelo grupo e é verbalizado de forma positiva. Todas se revelam como cuidadoras responsáveis e se sentem felizes como tal. Em todas as falas, a gestação possibilitou o amadurecimento e o domínio da situação por parte da adolescente. Revelam-se mães adolescentes conscientes de seu papel na família nuclear, na criação dos filhos, nos planos para o futuro. Sou mãe adolescente e gosto de ser assim revela a decisão da adolescente pela maternidade, mesmo não sendo planejada a gestação em alguns casos; revela o livre arbítrio da adolescente na manutenção da gestação e o quanto valoriza o apoio da mãe e do companheiro durante 0 processo da gestação e da construção da resiliência.

0 enfoque da resiliência denota uma necessidade de mudança de paradigma que inclui a passagem do modelo médico tradicional, centrado na fraqueza e na doença, para outra perspectiva, que inclui a capacidade de enfrentamento, 0 estímulo às potencialidades, a consideração da esperança, como componentes indispensáveis no desenvolvimento das pessoas. Nesse sentido, o processo saúde-doença da gestação na adolescência, como é visto pela maioria dos trabalhos na área, neste estudo, revelou uma mudança do processo saúde-doença para o processo saúde-resiliência, pois a gestação não foi verbalizada como um acontecimento negativo que prejudicasse ou impossibilitasse a trajetória de vida das adolescentes. A gestação trouxe mudanças de comportamento, amadurecimento, mudanças familiares e desenvolvimento dos fatores resilientes que foram preponderantes na construção da resiliência. As adolescentes gestantes vivenciaram o desenvolvimento do processo gestacional, elaboraram os fatores da resiliência, foram capazes de superar as adversidades e se tornaram mães adolescentes conscientes do seu papel e responsáveis.

\section{CONSIDERAÇÕES FINAIS}

Durante todo o desenvolvimento deste estudo, procurei aprofundar a questão da gestação na adolescência sem deixar de aprofundar na questão da resiliência, pois sempre me deparei com vários tipos de grupos de pessoas. As que não conseguem superar os conflitos que a vida lhes impõe; mas, também, as que conseguem superar e aprender com as experiências, mesmo estas sendo de extrema dificuldade.

0 apoio oferecido pelos pais às gestantes e às novas famílias após o nascimento dos bebês reflete uma mudança de comportamento bastante significativa, pois, além de apoiar e ajudar as filhas adolescentes nos cuidados durante e após a gravidez, as famílias se comprometem com a ajuda e apoio ao casal e bebê. As famílias se ajustam às necessidades e buscam conviver em harmonia. Esse fato foi importante na construção da resiliência das adolescentes desta pesquisa.

Os programas de prevenção de riscos e promoção da resiliência com adolescentes poderão ser desenvolvidos, levando-se em conta as especificidades de cada grupo, sua cultura, seus anseios, suas competências pessoais e grupais, e, principalmente, seus projetos de vida. Esses programas encontram-se fundamentados no conhecimento dos fatores de risco e de proteção existentes em determinado indivíduo, contexto e momento. Nesta abordagem, a estratégia básica deve ser centrada no indivíduo e no grupo social, os quais estão expostos ao agravo, e deve ajudar a reforçar, viabilizar, desenvolver habilidades e competências individuais e coletivas que permitam enfrentar e superar o evento, consequentemente, a qualidade de vida e de inserção no convívio social. Portanto, o modelo atual de assistência à gestante adolescente deve ser reformulado e reestruturado, buscando estratégias de ação voltadas às adolescentes e a seus grupos de convivência. Cabe ao profissional a compreensão de todos os fatores de risco a que o referido grupo está sujeito, principalmente, os fatores relacionados à família, à escola e à comunidade. Ressalta-se aqui a necessidade de um acompanhamento, se possível, multiprofissional, pois os diferentes saberes propiciam a almejada assistência integral à adolescente e a sua família de origem.Outros estudos devem ser realizados enfocando a continuidade do processo gestacional na adolescência, pois não sabemos qual será a situação dessas mães adolescentes num período futuro. Acreditamos que a continuidade do processo poderá ser acompanhada utilizando-se as abordagens preconizadas pela resiliência, isto é, envolvendo o contexto cultural, social, os fatores de risco a que estão sujeitas, no sentido de avaliar se as habilidades resilientes desenvolvidas no período gestacional foram suficientes para manter a continuidade da qualidade de vida do grupo.

\section{REFERÊNCIAS}

1- Maakaroum MF. Considerações gerais sobre adolescência. In: Maakaroum MF, Souza RP, Cruz AR, coordenadores. Tratado de adolescência: um estudo multidisciplinar. Rio de Janeiro: Cultura Médica; 1991. p. 1-54.

2- Baleeiro MC, Siqueira MJ, Cavalcanti RC, Souza V. Sexualidade do adolescente: fundamentos para uma ação educativa. Belo Horizonte: Secretaria de Estado da Educação/Secretaria de Estado da Saúde de Minas Gerais; 1999.

3- Alegria FLV, Schor N, Siqueira AAF. Gravidez na adolescência: estudo comparativo. Rev Saude Publica. 1989; 23(6):473-77. 
4-Monteiro DLM, Cunha AA, Reis AFF. Rsik factors in teeenagers preganacy. Int J Obstetr Ginecol. 1994; 46 (supl 1):88

5- Cunha AA, Monteiro DLM, Reis AAF. Fatores de risco da gravidez na adolescência. In: Monteiro DLM, Cunha AA, Bastos AC, editores. Gravidez na adolescência. Rio de Janeiro: Revinter; 1998. p. 43-56

6- Mandu ENT. Gravidez na adolescência: um problema? In: Ramos FRS, Monticelli M, Nitschke RG, organizadoras. Projeto Acolher: um encontro da enfermagem com o adolescente brasileiro. Brasília(DF): ABEn; 2000. p. 94-7.

7- Gualda DMR, Hoga LAK. Pesquisa qualitativa em enfermagem. Rev Esc Enferm USP.1997; 31(3): 410-22.

8- Andraus LMS, Minamisava R, Guimarães MF, Tavares VH. Gravidez e parto de adolescentes em maternidade pública. In: Ramos FRS, Monticelli M, Nitschke RG, organizadoras. Projeto Acolher: um encontro da enfermagem com o adolescente brasileiro. Brasília(DF): ABEn; 2000. p.105-109

9-Gurgel MCl,Alves MDS,Vieira NFC, Pinheiro PC, Barroso Gt. Gravidez na adolescência: tendência na produção científica de enfermagem. Esc Anna Nery. 2008: 12(4):799-05.

10- Sant'anna MJC, Coates V. Gravidez na adolescência: visão do hebiatra. In: Coates V, Beznos GW, Françoso LA. Medicina do adolescente.. $2^{\mathrm{a}}$ ed. São Paulo: Savier; 2003.

11- Coates V, Sant'anna MJC. Gravidez na adolescência. In: Françoso LA, Gejer D, Reato LFN. Sexualidade e saúde reprodutiva na adolescência. São Paulo: Atheneu; 2001

12- Loustanau MO, Sobo EJ. The cultural context of health, illness, and medicine.Westport: Bergin e Garvey; 1991.

13. Frank AW. When bodies need voices. In: Frank AW. The wounded storyteller: body, illness and ethics .Chicago: Chicago Press; 1995. p.1225.

14- Munist M, Santos H, Kotliarenco MA, Ojeda ENS, Infante F, Grotberg EH. Manual de identificación y promoción de la resiliencia en niños y adolescentes [texto na Internet]. Washington, DC: OPAS/OMS; 1998. [citado 2005 maio 27]. Disponivel em: http://www.paho.org/Spanish/HPP/HPF/ ADOL/Resilman.PDF

15- Helman CG. Cultura, saúde e doença. $2^{\mathrm{a} e d}$. Porto Alegre: Artes Médicas; 1994.

16- Lassiter EL. The Chicago guide to collaborative ethnography. Chicago: Chicago Press; 2005.

17- Meihy JCSB. Augusto e Lea: um caso de (des)amor em tempos modernos. São Paulo: Contexto; 2006.

18- Borkowski JG, Whitman T, Farris IR. Adolescent mothers and their children: risks, resilience, and development. In: Borkowski JG. Risk and resilience: adolescent mothers and their children grow up. Mahaw: Lawrence Eribaum Associates; 2007. 